Published in final edited form as:

Sturm, M., Gutowski, O., \& Brezesinski, G. (2019). The influence of calcium traces in ultrapure water on the lateral organization in tetramyristoyl cardiolipoin monolayers. ChemPhysChem, 20(11), 1521-1526. doi:10.1002/cphc.201900126.

\title{
The Influence of Calcium Traces in Ultrapure Water on the Lateral Organization in Tetramyristoyl Cardiolipin Monolayers
}

\author{
Marina Sturm, Olof Gutowski, Gerald Brezesinski
}

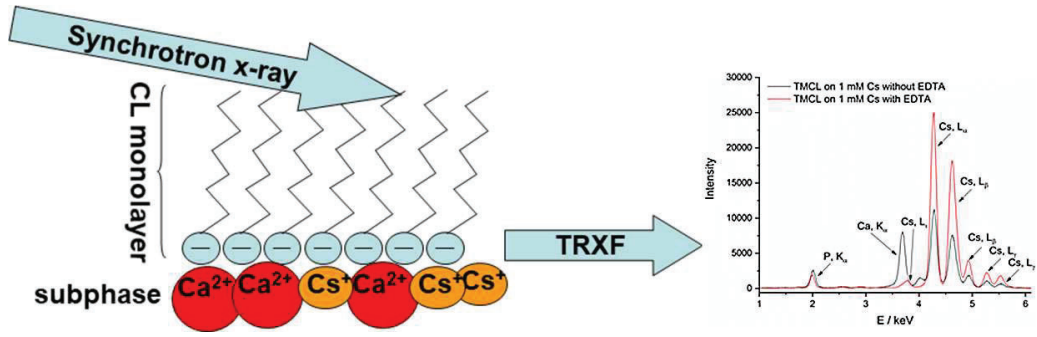

Traces of divalent calcium ions in Millipore water successfully compete with $1 \mathrm{mM}$ monovalent cesium ions in the electrical double layer of anionic cardiolipin (CL) monolayers. CL plays an important role in the structural organization of biological membranes, but the acidic properties of the phosphate head groups are still not sufficiently investigated. Traditional surface pressure-molecular area isotherm experiments combined with total-reflection X-ray fluorescence and grazing-incidence $X$-ray diffraction show the dominating role of calcium traces on the thermodynamic and structural properties of $\mathrm{CL}$ monolayers.

This article may be used for non-commercial purposes in accordance with Wiley Terms and Conditions for Self-Archiving. 


\title{
The Influence of Calcium Traces in Ultrapure Water on the Lateral Organization in Tetramyristoyl Cardiolipin Monolayers
}

\author{
Marina Sturm ${ }^{[b]}$ Olof Gutowski, ${ }^{[c]}$ and Gerald Brezesinski ${ }^{*[a]}$
}

Cardiolipin $(\mathrm{CL})$ plays an important role in administering the structural organization of biological membranes and therefore helps maintaining the integer membrane functionality. $\mathrm{CL}$ has a dimeric structure consisting of four acyl chains and two phosphate groups. With its unusual structure, the phospholipid is responsible for curvature formation in $\mathrm{CL}$ containing biological membranes. The acidic properties of the phosphate head groups are still not sufficiently investigated since there are controversial results in literature. The main aim of this work was to gain deeper insights into the influence of the $\mathrm{pH}$ on the ionization degree of CL. During the experiments, it became clear that the used ultrapure water contained traces of calcium. These unexpected calcium ions had a major impact on the behavior of $\mathrm{CL}$ monolayers. Therefore, the focus was put on the analysis of $\mathrm{CL}$ layers without and with EDTA in the subphase used to complex divalent calcium ions. For the analyses, traditional surface pressure $(\pi)$ - molecular area $(A)$ isotherm experiments combined with total reflection $\mathrm{x}$-ray fluorescence (TRXF) and grazing incidence $x$-ray diffraction (GIXD) have been used.

\section{Introduction}

The anionic phospholipid cardiolipin $(\mathrm{CL})$ has been found in bacterial and mitochondrial membranes. ${ }^{[1]}$ There, it fulfills a crucial function in maintaining the integer functionality of biological membranes as it takes part in regulating their structural organization. ${ }^{[2]}$ The reasons for that important feature of $\mathrm{CL}$ are based in its dimeric structure. ${ }^{[3]}$ With four alkyl chains and a relatively small head group, the phospholipid features a conical shape which induces negative curvature formation in $\mathrm{CL}$ containing membranes. ${ }^{[4-7]}$ Modifying the packing of the lipid can lead to structural changes and instabilities in the shape of the membrane..$^{[1,8,9]}$ By means of controlled environmental alterations, these changes can be investigated.

Langmuir monolayers represent only half of a membrane at the air/water interface. Therefore, they are conveniently used as

[a] Prof. Dr. G. Brezesinski

Biomolecular Systems

Max Planck Institute of Colloids and Interfaces

Science Park Potsdam-Golm, Am Mühlenberg 1, 14476 Potsdam, Germany E-mail: brezesinski@mpikg.mpg.de

[b] M. Sturm

Institute of Physics

University of Greifswald

Felix-Hausdorff-Str. 6, 17489 Greifswald, Germany

and

Biomolecular Systems

Max Planck Institute of Colloids and Interfaces

Science Park Potsdam-Golm, Am Mühlenberg 1, 14476 Potsdam, Germany E-mail: marina.sturm@mpikg.mpg.de

[c] O. Gutowski

Photon Science

Deutsches Elektronen-Synchrotron DESY

Notkestr. 85, 22607 Hamburg, Germany

E-mail: olof.gutowski@desy.de

Supporting information for this article is available on the WWW under https://doi.org/10.1002/cphc.201900126 model membrane systems because of stability and easy manipulation of composition and packing density in a very precise manner. ${ }^{[10-14]}$ However, Langmuir monolayers have clear drawbacks. All phospholipid monolayers are metastable systems. Transmembrane processes and the incorporation of proteins cannot be investigated. However, interactions of the membrane surface with peptides or nanoparticles dissolved in the subphase can be studied in one-component systems or in mixtures. ${ }^{[15-20]}$ The subphase conditions can be varied in a defined way allowing the study of the influence of subphase $\mathrm{pH}$ or ionic strength. ${ }^{[21,22]}$

The Langmuir monolayer technique is based on recording surface pressure $(\pi)$ - molecular area $(A)$ isotherms. Initially, a water insoluble lipid monolayer is spread onto an aqueous subphase. Upon compression, the packing density of the lipids is increasing and phase transitions can be triggered. In the socalled liquid-expanded (LE) phase, the hydrophobic chains are in an unordered (gauche) state. In the course of compression, a first-order phase transition identifies the change from the LE to the liquid-condensed (LC) phase. This first-order phase transition can be recognized by a plateau region in which both phases coexist. The hydrophobic chains are in an ordered (alltrans) state in the condensed phases, and the lipid film is less compressible. Many different condensed phases with tilted or non-tilted chains are described. ${ }^{[23]}$ The method of choice to characterize condensed phases on an angstrom scale is grazing incidence x-ray diffraction (GIXD). Maximal surface sensitivity is gained by using an incident angle of the synchrotron beam below the critical angle in order to reach total external reflection conditions. An evanescence wave travels along the interface and decays exponentially in the medium.

In order to achieve a better understanding about the properties of $1,1^{\prime}, 2,2^{\prime}$-tetramyristoyl cardiolipin ( $\left.T M C L\right)$, the study of $\mathrm{pH}$ influence is an important task of such inves- 
tigations. As a major phospholipid of the inner mitochondrial membrane, the charge of $\mathrm{CL}$ is essential for the electrostatic properties at the membrane. ${ }^{[24,25]}$ The acidic properties of the two phosphate head groups remain still controversial in $\mathrm{CL}$ research. While first studies reported strong acidic properties of both phosphate groups, ${ }^{[26]}$ completely different pKa values were discussed later. ${ }^{[27,28]}$ The model of a resonance-stabilized acid-anion was established for several years. Meanwhile, the research reveals again low pKs values for both $C L$ phosphate groups. ${ }^{[25,29]} \mathrm{A}$ study on the modification of the lipid-packing in model membranes based on changes in $\mathrm{pH}$ showed that lowering the $\mathrm{pH}$ results in instabilities of the membrane


it is evident that further studies on the $\mathrm{pH}$ dependent ionization degree of $\mathrm{CL}$ are required for a more profound understanding of the function of this phospholipid in biological membranes.

During our studies of TMCL monolayers on subphases with different $\mathrm{pH}$ values, a puzzling behavior of the $\pi-A$ isotherms appeared. Later performed total reflection $\mathrm{x}$-ray fluorescence (TRXF) measurements showed that the used ultrapure water (Millipore water) contained traces of calcium. The calcium ions competed successfully for interactions with the negatively charged head groups of TMCL with the monovalent cation (cesium) used for the TRXF experiments even if the concentration of $\mathrm{Cs}^{+}$was manifold higher than the $\mathrm{Ca}^{2+}$ concentration. Therefore, this study emphasizes the need of using a watersoluble complexing agent as ethylenediaminetetraacetic acid (EDTA) if working with anionic phospholipids. The influence of calcium traces in the ultrapure water is impressively documented by using conventional isotherm measurements combined with TRXF and GIXD.

\section{Experimental Section}

\section{Materials and Monolayer Preparation}

The ammonium salt of 1,1',2,2'-tetramyristoyl cardiolipin (TMCL, C14:0, purity $>99 \%)$ was purchased from Avanti Polar Lipids, Alabaster, AL, USA. Chloroform $\left(\mathrm{CHCl}_{3}\right.$, purity $\left.>99 \%\right)$ was obtained from VWR, Vienna, Austria. Cesium hydroxide monohydrate $(\mathrm{CsOH}$, purity $\geq 90.0 \%$ ), EDTA (purity $\geq 99.9 \%)$ and phosphoric acid $\left(\mathrm{H}_{3} \mathrm{PO}_{4}\right.$ purity $\geq 99.9 \%$ ) were purchased from Sigma Aldrich $\mathrm{GmbH}$, Taufkirchen, Germany. Boric acid $\left(\mathrm{H}_{3} \mathrm{BO}_{3}\right.$, purity $\left.>99 \%\right)$ was obtained from Merck KGaA, Darmstadt, Germany, and citric acid monohydrate $\left(\mathrm{C}_{6} \mathrm{H}_{8} \mathrm{O}_{7} \times \mathrm{H}_{2} \mathrm{O}\right.$, purity $\left.\geq 99.5 \%\right)$ from Carl Roth $\mathrm{GmbH}$, Karlsruhe, Germany.

For the monolayer experiments, the powdered TMCL was dissolved in chloroform. The solutions were spread by a micro-syringe onto subphases containing $1 \mathrm{mM}$ cesium. Depending on the desired bulk $\mathrm{pH}, 1 \mathrm{mM}$ cesium hydroxide was adjusted with citric acid, phosphatidic acid or boric acid.

The $\pi-A$ isotherms were recorded on a computer-interfaced Langmuir trough (R\&K, Potsdam, Germany) equipped with a Wilhelmy balance system after a waiting time of $10 \mathrm{~min}$ to assure complete solvent evaporation. The surface tension of water $\sigma_{w}$ measured with a filter paper Wilhelmy plate, decreases with increasing concentration of amphiphilic molecules in the monolayer at the surface $\left(\sigma_{\mathrm{F}}\right)$. The surface pressure $\pi \sigma_{\mathrm{w}} \quad \sigma_{\mathrm{F}}$ is plotted versus the molecular area A. A constant temperature was adjusted and stabilized using a recirculation cooler. The compression speed of the film was $5 \AA^{2}$ molecule ${ }^{1} \mathrm{~min}{ }^{1}$. All isotherms were measured at least twice for reproducibility.

\section{GIXD Experiments}

The GIXD experiments were performed at the high resolution diffraction beamline P08 (PETRA III, DESY, Hamburg, Germany). For the measurements, a Langmuir trough was located in a hermetically sealed container with Kapton windows transparent for $\mathrm{x}$-rays. The trough was constantly flushed with helium (He) to avoid scattering of molecules from the air and to increase the signal to background ratio considerably. The synchrotron beam was monochromated by a set of two monochromators (Silicon double crystal (Si111) and a Germanium double crystal (Ge311)). The photon energy was adjusted to $15 \mathrm{keV}$ corresponding to a wavelength of $0.827 \AA$. Approximately $2 \mathrm{~mm} \times 50 \mathrm{~mm}$ of the monolayer surface were illuminated. The incident angle was adjusted to $0.07^{\circ}$ to be below the critical angle for total external reflection for water. In order to reduce mechanically excited surface waves, a glass block was present in the subphase beneath the illuminated area of the monolayer. A Mythen (microstrip system for time resolved experiments) detector (DECTRIS, Baden, Switzerland) was rotated around the sample to detect the intensity of the diffracted beam as a function of the vertical scattering angle $\alpha_{f}$ and horizontal scattering angle 20. A Soller collimator (JJ X-RAY, Denmark) was located between the sample and the detector to restrict the in-plane divergence of the diffracted beam.

The integration and representation of the diffraction peaks was succeeded using a MatLab macro. Model peaks taken as Lorentzian in the in-plane (Bragg peaks, $Q_{x y}$ ) and Gaussian in the out-of-plane direction (Bragg rods, $Q_{z}$ ) were fitted to the integrated data. Subsequently, the Bragg peak positions respectively the centers of the Bragg rods are obtained and structure relevant information is gained. The presence of one Bragg peak located at the horizon describes a hexagonal lattice of non-tilted lipid alkyl chains, two peaks are typical for an orthorhombic and three peaks for an oblique lattice. ${ }^{[23,30-33]}$

\section{TRXF Experiments}

During the last years, TRXF was established as an element-specific complementary scattering technique. ${ }^{[34-36]}$ The TRXF measurements were partly carried out at beamline P08 (PETRA III, DESY, Hamburg, Germany). The above described setup was used. The fluorescence signal was detected by an Amptek X-123SDD detector (Amptek, Bedford, United States of America) placed almost parallel to the liquid surface and perpendicular to the photon beam axis. This detector position was chosen in order to keep the Compton scattering at the given polarization of the photons as low as possible. The footprint center of the incident beam was adjusted to the middle of the trough at the middle of the view angle of the fluorescence detector.

TRXF measurements were also performed at beamline SIRIUS (SOLEIL, Gif-sur-Yvette Cedex, France). The sealed container with the Langmuir trough was flushed with Helium. Instead of using a glass plate, the setup was located on an anti-vibration table to prevent interferences. The photon energy was set to $10.5 \mathrm{keV}$, corresponding to a wavelength of $1.180 \AA$, at an incidence angle of $0.1^{\circ}$. The signal detection was performed by a single element silicon drift detector which was located inside the trough horizontal to the water surface. 

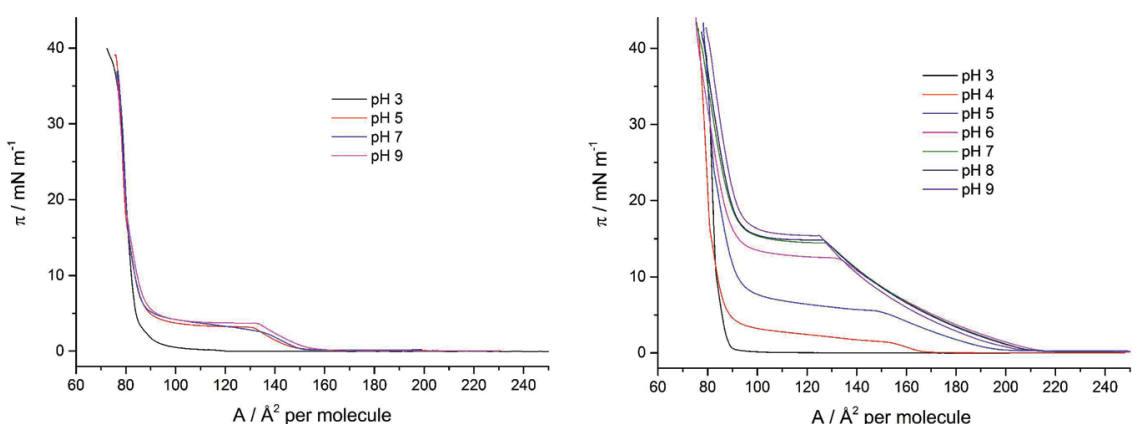

Figure 1. Pressure-area $(\pi-A)$ isotherms of TMCL monolayers on subphases containing $1 \mathrm{mM}$ Cs without (left) and with (right) $0.1 \mathrm{mM}$ EDTA. Due to the binding of the divalent $\mathrm{Ca}^{2+}$ ions, the LE-LC phase transition shifts to higher pressures with increasing pH. The measurements were carried out at $20^{\circ} \mathrm{C}$

\section{Results and Discussion}

properties of TMCL monolayers were investigated on subphases containing $1 \mathrm{mM}$ cesium ions because of the planned TRXF experiments. TRXF was the method of choice to determine the ionization degree of the phosphate head groups based on the concentration of the corresponding counterions in the electrical double layer (EDL) near a charged surface. Cesium has been chosen as the most suitable chemical element for such experiments not because of biological importance but because it provides a significant fluorescence signal in the accessible energy range of the corresponding synchrotron beamlines (P08 at PETRA III and SIRIUS at Soleil). The TRXF signal intensity is directly proportional to the $\mathrm{Cs}^{+}$concentration in the EDL. To avoid competition between different cations, the used subphase should only contain one type of cation. GIXD can be simultaneously measured and provides information about the structure of condensed monolayer phases.

The first experiments were conducted assuming that no other cations besides cesium were in the subphase. However, the $\pi-\mathrm{A}$ isotherms exhibited an unexpected behavior. ${ }^{[37,38]}$ The isotherm at $\mathrm{pH} 3$ is typical for a monolayer which does not form a liquid-expanded (LE) phase (Figure 1). The gas-analogous state transforms during compression directly into a condensed (LC) state (re-sublimation) at practically zero lateral pressure. Only at higher $\mathrm{pH}$ values, the typical first-order phase transition between LE and LC can be seen. However, the transition pressure is almost the same in the $\mathrm{pH}$ range between 5 and 9. It is expected that the ionization degree of the head groups increases with increasing $\mathrm{pH}$. However, this result would indicate that the head groups are already completely deprotonated at $\mathrm{pH} 5$. Inspection of the TRXF spectrum showed that obviously $\mathrm{Ca}^{2+}$ ions are present in the EDL. Subsequently performed TRXF measurements using highly charged behenylsulfate monolayers on pure Millipore water (no addition of cesium salt) indicate the presence of calcium in water with a resistivity value of $18.2 \mathrm{M} \Omega \mathrm{cm}$, which ensures an overall concentration of ions below $1 \mathrm{ppb}(1 \mu \mathrm{g} / \mathrm{l})$. $^{[39]}$ Traces of calcium in the used water led to a competition between calcium and cesium ions for interactions with the negatively charged TMCL head groups. The effective amount of the calcium traces in the highly purified water is not determined but the influence on the interactions of $\mathrm{Cs}^{+}$ions with the monolayer head groups is grave. The charged TMCL head groups favor interacting with divalent calcium ions instead with the monovalent cesium ions. Therefore, a second set of experiments has been conducted with the addition of $0.1 \mathrm{mM}$ ethylenediaminetetraacetic acid (EDTA) to the subphase containing $1 \mathrm{mM}$ cesium ions in order to bind the competing calcium ions. ${ }^{[40]}$ In the calcium complex, EDTA is a tetradentate ligand, and chelation involves the two nitrogen atoms and two oxygen atoms in separate carboxyl groups. The chelating ability of EDTA depends on the $\mathrm{pH}$ value. A range from $\mathrm{pH} 5$ to 14 for chelating $\mathrm{Ca}^{2+}$ ions is recommended. Below pH 5.5, $\mathrm{Ca}^{2+}$ is no longer effectively chelated by EDTA, even that all 4 carboxyl groups are deprotonated (pKa values of $0.3,1,2.6$ and 2.8). The pKa values of the 2 amino groups are 6.1 and 10.2. In Figure 1, the $\pi-A$ isotherms of TMCL on subphases containing $1 \mathrm{mM}$ cesium without (left) and with $0.1 \mathrm{mM}$ EDTA (right) are compared. The effective binding of $\mathrm{Ca}^{2+}$ ions by EDTA is reflected in the course of the isotherms. Without EDTA, $\mathrm{Ca}^{2+}$ ions interact effectively with the phosphate head groups of the TMCL monolayer. The LE-LC phase transition is strongly influenced by the interaction with the calcium ions. The increase of the $\mathrm{pH}$ values from 5 to 9 should on one hand increase the deprotonation degree of the head group and therefore increase the electrostatic repulsion between the negatively charged head groups. This increased repulsion should lead to an increase of the transition pressure (a higher compression rate is needed to induce the nucleation of the condensed phase). On the other hand, more calcium is attracted to the higher charged head groups. The divalent calcium ions have obviously a condensing effect and should reduce the transition pressure from LE to LC. These two events compensate each other leading to an almost $\mathrm{pH}$ independent transition pressure in the $\mathrm{pH}$ range between 5 and 9. In contrast, the phase transition pressure is increasing continuously with increasing $\mathrm{pH}$ at least up to $\mathrm{pH} 8$ if EDTA is present in the subphase. It is worth comparing the transition pressures $\pi_{\mathrm{t}}$ at high $\mathrm{pH}$ values $\left(\mathrm{pH}\right.$ 8): $\pi_{\mathrm{t}}$ is 4-times higher with EDTA in the subphase compared to experiments with no EDTA in the subphase $(16 \mathrm{mN} / \mathrm{m}$ and $4 \mathrm{mN} / \mathrm{m}$, respectively).

It is interesting to note that the plateau region in the experiments with EDTA in the subphase is not always horizontal but inclined. This is particularly pronounced at $\mathrm{pH} 4$ and 5 . The 
only reasonable explanation is the coexistence of $\mathrm{TMCL}$ molecules with different ionization states. For all other $\mathrm{pH}$ values, the deviation of the plateau from the horizontal is much smaller indicating that most of the molecules are in the same ionization state.

To quantify the ionization state of the TMCL head groups, TRXF measurements were performed on subphases with different $\mathrm{pH}$ values. The negatively charged phosphate groups of TMCL attract positively charged ions from the subphase in order to form the EDL. One important requirement of the quantification procedure is to avoid any competition of cations for interactions with the charged head groups. Therefore, the subphase should contain only one type of cation. However, the analysis of the TRXF spectra indicated that the system contains traces of calcium ions.

In Figure 2, the TRXF spectra of TMCL monolayers on subphases containing $1 \mathrm{mM}$ cesium without and with $0.1 \mathrm{mM}$ EDTA are compared. EDTA binds effectively divalent cations above $\mathrm{pH}$ 5. The spectrum, taken at $\mathrm{pH} 7$, shows clearly the presence of calcium ions in the EDL if no EDTA is added to the subphase. EDTA binds all the calcium traces, and a twofold higher intensity of the cesium line is observed. At this stage, we cannot quantify the exact amount of calcium in the used Millipore water. More TRXF experiments with different $\mathrm{Cs}^{+} / \mathrm{Ca}^{2+}$ ratios are needed. Besides an intensity increase of the cesium lines in general, the binding of $\mathrm{Ca}^{2+}$ by EDTA uncovers an additional cesium line $\left(L_{1}\right)$ in the spectrum. For the measurement without EDTA in the subphase, the Cs $L_{1}$ line is hidden by the $\mathrm{Ca} \mathrm{K}_{\alpha}$ line.

To obtain additional information of the influence of calcium traces in the used water on the TMCL monolayer structures at a defined $\mathrm{pH}$ value, GIXD has been applied to determine the chain lattice structure at lateral pressures above the first-order LE-LC phase transition. For each experiment, the structural

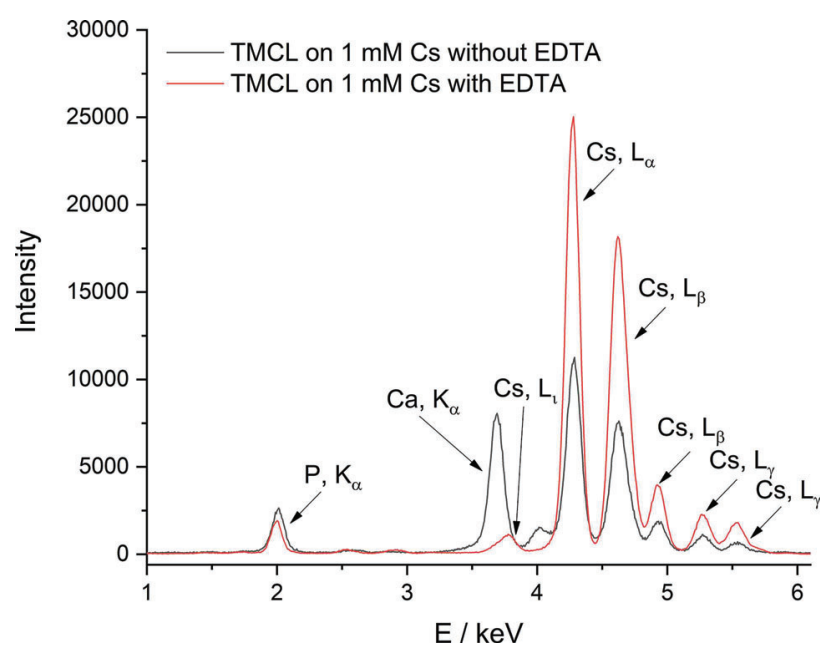

Figure 2. TRXF spectra (fluorescence intensity vs. photon energy E) of TMCL on subphases containing $1 \mathrm{mM}$ cesium without (black) and with (red) $0.1 \mathrm{mM}$ EDTA at $\mathrm{pH} 7$ and $20^{\circ} \mathrm{C}$. EDTA binds effectively calcium at $\mathrm{pH}$ values above 5 . The cesium $L_{1}$ line is only visible when EDTA is present in the subphase. changes were recorded in the course of monolayer compression.

In Figure 3, the contour plots of the diffracted x-ray intensities versus the in-plane $\left(Q_{x y}\right)$ and out-of-plane $\left(Q_{z}\right)$ components of the scattering vector are presented at different lateral pressures along the isotherm on subphases with $\mathrm{pH} 6$ (see also table $\mathrm{S} 2$ in $\mathrm{SI}$ ). At $15 \mathrm{mN} / \mathrm{m}$, the in-plane structure of TMCL on a subphase containing $1 \mathrm{mM}$ cesium without EDTA (Figure 3, top) is characterized by two Bragg peaks (see also Figure $\mathrm{S} 1$ in $\mathrm{SI}$ ) indicative of an orthorhombic structure with tilted chains $\left(\mathrm{L}_{2}\right)$. Compression results in a reduction of the tilt angle leading finally to a hexagonal packing of non-tilted chains indicated by one Bragg peak at the horizon (hexatic LS phase). ${ }^{[23]}$ This result is qualitatively the same as described in literature but quantitatively different. ${ }^{[41]}$

The addition of $0.1 \mathrm{mM}$ EDTA leads to clear changes (Figure 3, bottom). At $14 \mathrm{mN} / \mathrm{m}$, the chains form an oblique LC structure characterized by 3 Bragg peaks above the horizon (see also Figure S1 in SI). Upon further compression, the tilt angle decreases and the in-plane phase structure changes initially to orthorhombic (between 22 and $26 \mathrm{mN} / \mathrm{m}$ ) and finally to hexagonal (above $30 \mathrm{mN} / \mathrm{m}$ ). As already known from $\pi-A$ isotherms, the calcium traces have a condensing effect (lower LE-LC transition pressure) on the TMCL monolayer. ${ }^{[42]}$ The calcium ions compete successfully with the cesium ions for interactions with the negatively charged TMCL head groups. At $15 \mathrm{mN} / \mathrm{m}$, the tilt angle on the calcium containing subphase is clearly smaller than on the EDTA containing subphase $\left(15^{\circ}\right.$ compared to $23^{\circ}$ ). Additionally, the phase sequence on compression is changed. In presence of calcium traces, the found structural sequence is $L_{2}-L S$, whereas after removal of $\mathrm{Ca}^{2+}$ by EDTA, the phase sequence is changed to obl- $\mathrm{L}_{2}-\mathrm{LS}$.

The determination of the tilting transition pressure $\left(\tau_{t}\right.$, transition from a monolayer structure with tilted to a structure with non-tilted chains) assumes a constant cross-sectional area of the chains and an almost linear pressure-area relationship in the condensed state of the isotherm. ${ }^{[43]}$ The lattice distortion is a linear function of the $\sin ^{2}(\mathrm{t})$ according to a modified Landau theory, what is also valid for both subphases without and with EDTA (see Figure S2 in SI). ${ }^{[23,44]}$ The plots lead to zero distortion at zero tilt, typical for LS phases. The tilting transition pressure is yielded by the extrapolation of $1 / \cos (t)$ versus the lateral pressure $\pi$ to 1 . The corresponding results for TMCL on a subphase containing $1 \mathrm{mM}$ cesium as well as on a subphase containing $1 \mathrm{mM}$ cesium and $0.1 \mathrm{mM}$ EDTA are presented in Figure 4. Upon compression of the monolayer, the tilt angle of the chains decreases as well as the lattice distortion value. The cross-sectional area of the hydrocarbon chains in the LC phase remains almost constant during compression (20-20.2 $\AA^{2}$ ). Due to the presence of EDTA, the tilting transition pressure $\pi_{t}$ is increased by approximately $4 \mathrm{mN} / \mathrm{m}$. The correlation length is increasing during compression indicating a packing of the molecules with less defects in the LC domains. 

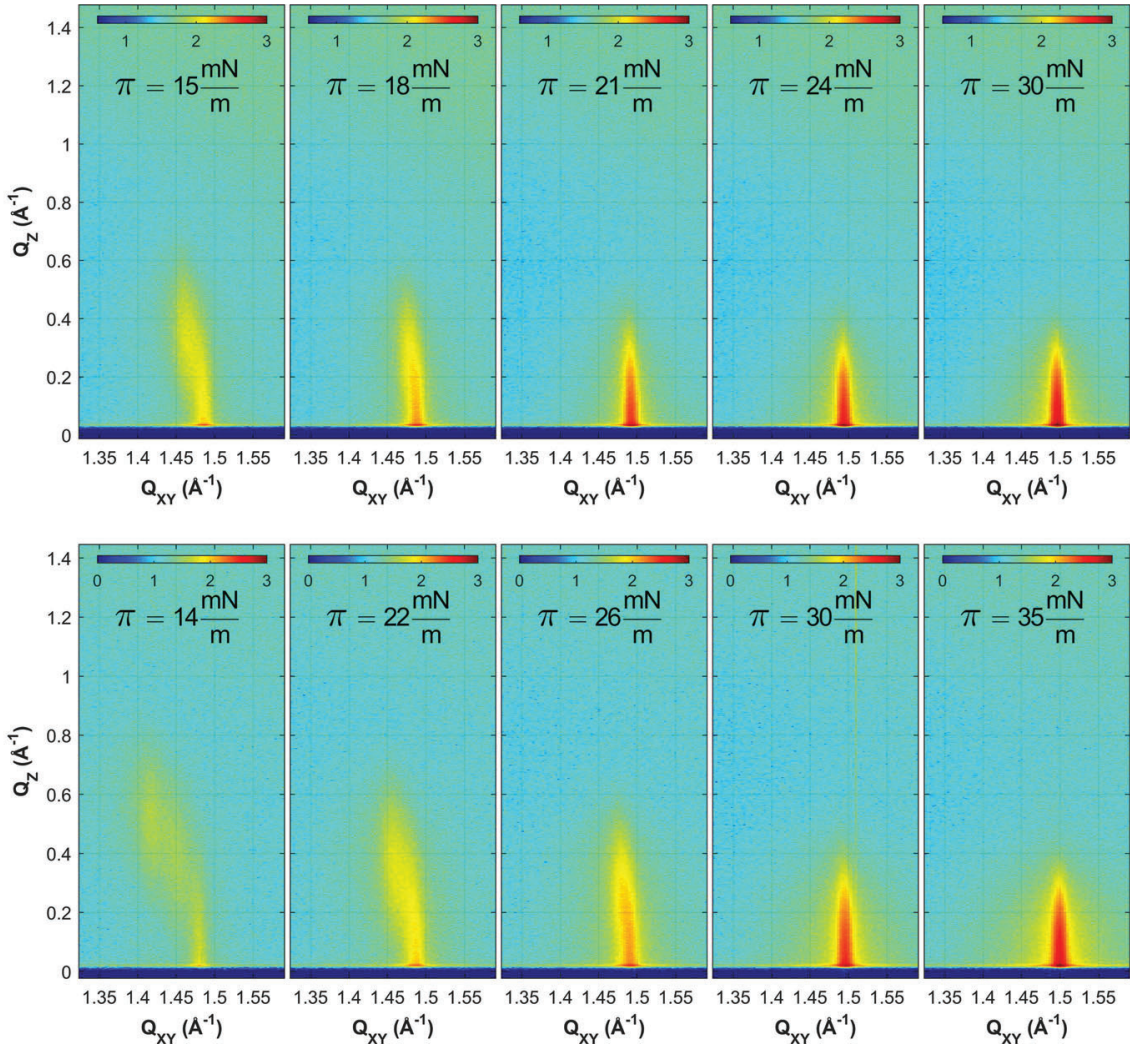

Figure 3. Selected contour plots of the $x$-ray intensities versus the in-plane $\left(Q_{x y}\right)$ and out-of-plane $\left(Q_{z}\right)$ components of the scattering vector of $T M C L$ on subphases at $\mathrm{pH}$ 6. The temperature was set to $20^{\circ} \mathrm{C}$. The lateral pressures are indicated. Top: subphase containing $1 \mathrm{mM} \mathrm{Cs}{ }^{+}$. Bottom: subphase containing $1 \mathrm{mM} \mathrm{Cs}^{+}$and $0.1 \mathrm{mM} \mathrm{EDTA}$

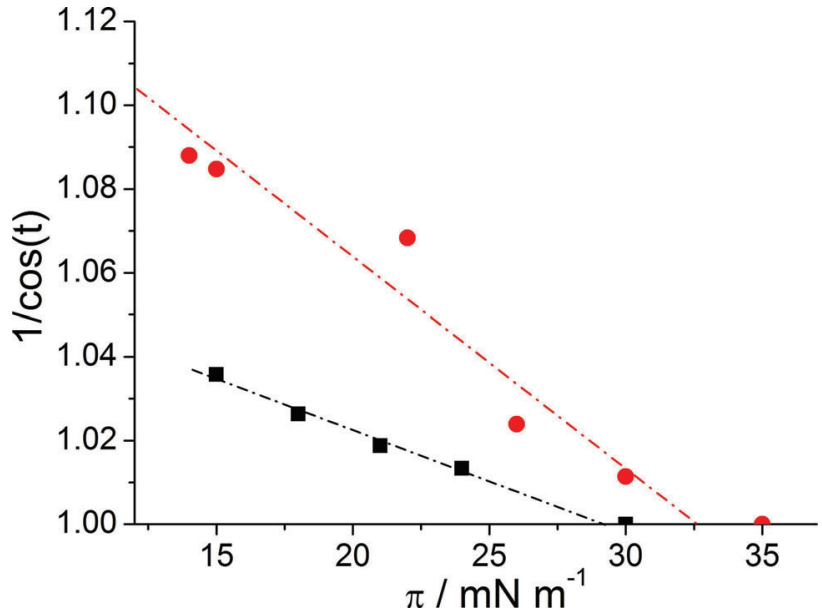

Figure 4. Determination of the tilting transition pressure $\pi_{t}$ by extrapolation of $1 / \cos (t)$ vs. the lateral pressure $\pi$ to 1 . TMCL on subphases containing $1 \mathrm{mM}$ cesium ( $\square$ ) and $1 \mathrm{mM}$ cesium with $0.1 \mathrm{mM}$ EDTA $(\bullet)$. With no EDTA in the subphase $\pi_{t}=28.9 \mathrm{mN} / \mathrm{m}$ and with EDTA $\pi_{t}=32.6 \mathrm{mN} / \mathrm{m}$. The lines are the corresponding linear fits to the data.

\section{Conclusions}

The results presented in this work show that the ultrapure water used for the experiments contained traces of calcium. The unexpected calcium ions in the subphase were detected by
TRXF. The divalent calcium ions compete successfully with the monovalent cesium ions for interactions with the negatively charged TMCL head groups. In order to bind the divalent calcium ions and to only allow cesium to interact with $\mathrm{TMCL}$, EDTA was added to the subphase. The influence of calcium traces can be seen in the $\pi-A$ isotherms by lower phase transition pressures. The almost constant transition pressure between $\mathrm{pH} 5$ and 9 could lead to a wrong conclusion about the ionization degree of the head groups. The isotherms taken after addition of EDTA, which complexes the calcium traces, indicate clearly that the head groups are only fully ionized above $\mathrm{pH}$ 8. The structural data obtained by GIXD emphasize the effect of calcium traces on TMCL monolayers. The interaction of calcium leads to a slightly different packing of the head groups causing a smaller in-plane area of the chains connected with a smaller tilt angle but a larger cross-sectional area. If $\mathrm{Ca}^{2+}$ is complexed by EDTA, the in-plane area and the tilt angle are larger but the cross-sectional area of the chains is smaller (restricted rotation around the chain axis). The phase sequences are different (obl- $\mathrm{L}_{2}$-LS with EDTA in the subphase and $\mathrm{L}_{2}-\mathrm{LS}$ with no EDTA added).

In conclusion, the results of this work are important for all scientists working with negatively charged monolayers especially if anionic phospholipids are used. It is crucial to check if the used ultrapure water contains traces of divalent cations. The addition of EDTA in such experiments is very important. 


\section{Acknowledgements}

We thank the Deutsche Forschungsgemeinschaft for financial support (RTG 1947). The Max Planck Institute of Colloids and Interfaces is acknowledged for providing the access to the laboratories. The synchrotron facilities DESY (Hamburg, Germany) and SOLEIL (Gif-sur-Yvette Cedex, France) are acknowledged for beamtime and support at the beamlines.

\section{Conflict of Interest}

The authors declare no conflict of interest.

[1] N. Khalifat, J.-B. Fournier, M. I. Angelova, N. Puff, Biochim. Biophys. Acta 2011, 1808, 2724-2733.

[2] M. Ren, C. K. Phoon, M. Schlame, Prog. Lipid Res. 2014, 55, 1-16.

[3] G. Paradies, V. Paradies, V. De Benedictis, F. M. Ruggiero, G. Petrosillo, Biochim. Biophys. Acta 2014, 1837, 408-417.

[4] C. Osman, D. R. Voelker, T. Langer, J. Cell Biol. 2011, 192, 7-16.

[5] L. D. Renner, D. B. Weibel, P. Natl. Acad. Sci. USA 2011, 108, 6264-6269.

[6] K. J. Boyd, N. N. Alder, E. R. May, Langmuir 2017, 33, 6937-6946.

[7] F. Elías-Wolff, M. Lindén, A. P. Lyubartsev, E. G. Brandt, Soft Matter 2019, $15,792-802$.

[8] J. D. Unsay, K. Cosentino, Y. Subburaj, A. J. García-Sáez, Langmuir 2013, 29, 15878-15887.

[9] A. Vergeade, C. C. Bertram, A. T. Bikineyeva, W. E. Zackert, S. S. Zinkel, J. M. May, S. I. Dikalov, L. J. Roberts, O. Boutaud, Mitochondrion 2016, 28, 88-95.

[10] H. M. McConnell, Annu. Rev. Phys. Chem. 1991, 42, 171-195.

[11] H. Brockman, Curr. Opin. Struct. Biol. 1999, 9, 438-443.

[12] G. Brezesinski, H. Möhwald, Adv. Colloid Interface Sci. 2003, 100, 563584.

[13] C. Stefaniu, G. Brezesinski, H. Möhwald, Adv. Colloid Interface Sci. 2014, 208, 197-213.

[14] M. D. Phan, K. Shin, J. Chem. Biol. Interfaces 2014, 2, 1-55.

[15] D. Gidalevitz, Y. Ishitsuka, A. S. Muresan, O. Konovalov, A. J. Waring, R. I. Lehrer, K. Y. C. Lee, P. Natl. Acad. Sci. USA 2003, 100, 6302-6307.

[16] F. Neville, M. Cahuzac, O. Konovalov, Y. Ishitsuka, K. Y. C. Lee, I. Kuzmenko, G. M. Kale, D. Gidalevitz, Biophys. J. 2006, 90, 1275-1287.

[17] K. Andreev, C. Bianchi, J. S. Laursen, L. Citterio, L. Hein-Kristensen, L. Gram, I. Kuzmenko, C. A. Olsen, D. Gidalevitz, Biochim. Biophys. Acta 2014, 1838, 2492-2502.
[18] K. Andreev, M. W. Martynowycz, M. L. Huang, I. Kuzmenko, W. Bu, K. Kirshenbaum, D. Gidalevitz, Biochim. Biophys. Acta 2018, 1860, 14141423.

[19] A. J. Sheridan, J. M. Slater, T. Arnold, R. A. Campbell, K. C. Thompson, Langmuir 2017, 33, 10374-10384.

[20] D. W. Britt, J. Buijs, V. Hlady, Thin Solid Films 1998, 327, 824-828.

[21] P. Garidel, A. Blume, Chem. Phys. Lipids 2005, 138, 50-59.

[22] T. Zhang, S. L. Brantley, D. Verreault, R. Dhankani, S. A. Corcelli, H. C. Allen, Langmuir 2018, 34, 530-539.

[23] V. M. Kaganer, H. Möhwald, P. Dutta, Rev. Mod. Phys. 1999, 71, 779-819.

[24] S. E. Horvath, G. Daum, Prog. Lipid Res. 2013, 52, 590-614.

[25] M. Sathappa, N. N. Alder, Biochim. Biophys. Acta 2016, 1858, 1362-1372.

[26] M. J. Coulon-Morelec, M. Faure, J. Maréchal, B. Soc. Chim. Biol. 1962, 44, $171-183$.

[27] M. Kates, J. Y. Syz, D. Gosser, T. H. Haines, Lipids 1993, 28, 877-882.

[28] T. H. Haines, Biochim. Biophys. Acta 2009, 1788, 1997-2002.

[29] G. Olofsson, E. Sparr, PLoS One 2013, 8, e73040.

[30] D. Jacquemain, S. G. Wolf, F. Leveiller, M. Deutsch, K. Kjaer, J. AlsNielsen, M. Lahav, L. Leiserowitz, Angew. Chem. Int. Ed. 1992, 31, 130152; Angew. Chem. 1992, 104, 134-158.

[31] K. Kjaer, Physica B 1994, 198, 100-109.

[32] J. Als-Nielsen, D. Jacquemain, K. Kjaer, F. Leveiller, M. Lahav, L. Leiserowitz, Phys. Rep. 1994, 246, 251-313.

[33] C. Stefaniu, G. Brezesinski, Curr. Opin. Colloid Interface Sci. 2014, 19, 216227.

[34] J. Daillant, L. Bosio, J. J. Benattar, C. Blot, Langmuir 1991, 7, 611-614.

[35] V. L. Shapovalov, M. E. Ryskin, O. V. Konovalov, A. Hermelink, G. Brezesinski, J. Phys. Chem. B 2007, 111, 3927-3934.

[36] W. Bu, D. Vaknin, J. Appl. Phys. 2009, 105, 084911.

[37] C. M. Knobler, R. C. Desai, Annu. Rev. Phys. Chem. 1992, 43, 207-236.

[38] R. Kensbock, H. Ahrens, C. A. Helm, Langmuir 2019, 35, 3624-3633.

[39] S. Mabic, B. Gerion, E. Castillo, I. Kano, LabManager Magazine 2007, 2, 17-21 (http://photos.labmanager.com/magazinePDFs/archives/labmanager200707-dl.pdf).

[40] T. M. Nobre, M. W. Martynowycz, K. Andreev, I. Kuzmenko, H. Nikaido, D. Gidalevitz, Biophys. J. 2015, 109, 2537-2545.

[41] F. Etienne, Y. Roche, P. Peretti, S. Bernard, Chem. Phys. Lipids 2008, 152, 13-23.

[42] A. D. Petelska, M. Naumowicz, J. Biol. Inorg. Chem. 2017, 22, 1187-1195.

[43] F. Bringezu, B. Dobner, G. Brezesinski, Chem. Eur. J. 2002, 8, 3203-3210.

[44] V. M. Kaganer, E. B. Loginov, Phys. Rev. E 1995, 51, 2237-2249. 